\title{
ORIGINAL ARTICLE \\ Acute effect of a cod protein hydrolysate on postprandial acylated ghrelin concentration and sensations associated with appetite in healthy subjects: a double-blind crossover trial
}

\author{
Hanna Fjeldheim Dale1,2,*, Caroline Jensen', Trygve Hausken',3, Einar Lied', Jan Gunnar \\ Hatlebakk1,2,3, Ingeborg Brønstad ${ }^{5,6}$, Dag Arne Lihaug Hoff7,8 and Gülen Arslan Lied 1,2,3 \\ 'Centre for Nutrition, Department of Clinical Medicine, University of Bergen, Bergen, Norway; ${ }^{2}$ Division of Gastroenterology, \\ Department of Medicine, Haukeland University Hospital, Bergen, Norway; ${ }^{3}$ National Centre of Functional Gastrointestinal \\ Disorders, Haukeland University Hospital, Bergen, Norway; ${ }^{4}$ Firmenich Bjørge Biomarin AS, Ellingsøy, Ålesund, Norway; \\ ${ }^{5}$ Department of Clinical Medicine, University of Bergen, Bergen, Norway; ${ }^{6}$ National Centre for Ultrasound in Gastroenterology, \\ Haukeland University Hospital, Bergen, Norway; ${ }^{2}$ Division of Gastroenterology, Department of Medicine, Ålesund Hospital, \\ Møre \& Romsdal Hospital Trust, Ålesund, Norway; ${ }^{8}$ Department of Clinical and Molecular Medicine, Faculty of Medicine and \\ Health Sciences, Norwegian University of Science and Technology, Trondheim, Norway
}

\section{Popular scientific summary}

- Ghrelin is an appetite-regulating hormone, with high concentrations before a meal and reduced concentrations after a meal. Compounds with the ability to suppress the action of ghrelin may be valuable for weight regulation.

- Fish protein hydrolysates are suggested to contain bioactive peptides capable of affecting glucose metabolism and body weight.

- In this study, no effect of a supplement with cod protein hydrolysate on postprandial ghrelin concentrations or sensations related to appetite was observed.

\section{Abstract}

Background: Fish protein hydrolysates are suggested to contain bioactive sequences capable of affecting metabolic pathways involved in the regulation of glucose metabolism and body weight when consumed in low doses. Modulation of the appetite-regulating hormone ghrelin may explain suppression of insulin secretion and weight loss observed in previous studies with fish protein hydrolysates.

Objective: This study aimed to assess the effect of a single, low dose of cod protein hydrolysate $(\mathrm{CPH})$ before a breakfast meal on postprandial acylated ghrelin concentration and sensations associated with appetite in healthy subjects. Design: In this explorative trial with a crossover design, 41 healthy individuals (15 males and 26 females, age $51 \pm 6$ years) completed 2 study days separated by 4-7 days of washout. On both study days, a test drink containing $20 \mathrm{mg} \mathrm{CPH}$ or casein (control) per kg body weight was given immediately before a standardized breakfast meal. Acylated ghrelin concentrations were measured before test drink/breakfast (baseline) and at time $0,20,40,80$, and 180 min postprandially. Sensations associated with appetite were measured by a Visual Analog Scale (100 mm) at baseline and 0, 20, 40, and $180 \mathrm{~min}$ postprandially.

Results: Statistically, no difference was observed between CPH and control for postprandial acylated ghrelin concentrations (mean difference geometric mean: $1.05 \mathrm{pg} / \mathrm{mL}, 95 \%$ confidence interval [CI]: 0.97-1.13, $P=0.266$ ), or between the total area under the curve (tAUC) for acylated ghrelin after CPH (tAUC $=17518 \mathrm{pg} / \mathrm{mL} \times \mathrm{min}$, 95\% CI: 0-47941) and control (tAUC $=17272 \mathrm{pg} / \mathrm{mL} \times \min , 95 \% \mathrm{CI}: 0-48048, P=0.991$ ). No differences were found between $\mathrm{CPH}$ and control for sensation of appetite, according to tAUC of postprandial scores for satiety $(P=0.794)$ and the feeling of fullness $(P=0.996)$.

Conclusion: We did not find an effect of a single dose of $\mathrm{CPH}$ on postprandial concentrations of acylated ghrelin or sensations related to feeling of hunger, compared to control. Further studies should aim to evaluate the effect of a supplement with $\mathrm{CPH}$ given daily over a period of time.

Keywords: hunger; overweight; marine peptides; gastric hormones; nutrition supplement 
$\mathrm{G}$ hrelin is a gastric hormone, capable of stimulating hunger and influence energy homeostasis (1). It is a small peptide consisting of 28 amino acids, secreted from neuroendocrine cells in the submucosal layer of the stomach (2). The circulating ghrelin concentration gradually increases before a meal and decreases with feeding (3). Two forms of ghrelin are present in the circulation, acylated and non-acylated ghrelin, of which the acylated form is the one known to activate the ghrelin receptor (2).

Acylated ghrelin is a natural ligand binding to the growth hormone secretagogue (GHS) receptor, leading to stimulation of the secretion of growth hormone $(\mathrm{GH})$, reduction in insulin secretion and glucose tolerance (4-6). Furthermore, it has been shown that acylated ghrelin holds potent adipogenic and orexigenic effects mediated through the GHS receptor located in the central nervous system (CNS) (4). Acylated ghrelin is known to directly activate pathways in the CNS controlling both parasympathetic and sympathetic nerve activity through GHS receptors (7) and possibly indirectly suppresses insulin secretion via neural signaling (8). These qualities have created the idea that compounds having the ability to suppress the action of ghrelin may be valuable for the prevention or treatment of overweight, obesity, insulin resistance, and abnormal lipid and glucose metabolism $(9,10)$.

In previous studies in rats and humans, it has been observed that the intake of low doses of peptides from fish is capable of beneficially influencing glucose metabolism (11-14), reducing adipose tissue mass, and improving serum fatty acid composition $(15,16)$, when compared to placebo or casein. In addition, some recent studies have found fish protein hydrolysates to beneficially influence hormones involved in the regulation of appetite, such as cholecystokinin (CCK) and glucagon-like peptide 1 (GLP-1), as well as influence the subjective feeling of craving sweets $(17,18)$, when compared to placebo in human subjects. The suggested effective daily dose based on the current literature in human subjects ranges from 1 to $6 \mathrm{~g}$ per day $(13,18)$. Consequently, the hypothesized effect of a fish protein hydrolysate is not due to the consumed protein per se, which is negligible compared to the normal recommended total daily dietary intake of a healthy individual (e.g. 65-80 g protein per day with body weight $80 \mathrm{~kg}$ ) (19). A possible mechanism for suppression of postprandial insulin concentration and weight loss could be modulation of postprandial ghrelin concentrations, and a low dose of fish protein hydrolysate is presumed to be effective due to the content of bioactive peptides with unique amino acid sequences (20). In the current trial, we hypothesize that a potential suppressing effect on appetite and postprandial ghrelin levels can be attributed to a high fraction of di- and tripeptides with branched-chain amino acids in the cod protein hydrolysate $(\mathrm{CPH})$, facilitating rapidly absorption from the gastrointestinal tract and possibly capable of influencing pathways involved in the regulation of appetite.

As metabolism and energy expenditure decrease with age, middle-aged individuals often experience weight gain. Thus, middle-aged individuals might benefit from an intervention targeting appetite and hunger regulation. Data on the specific effect of a dietary supplement with a fish protein hydrolysate on ghrelin concentrations and sensations associated with appetite have, to our knowledge, previously not been published. The present study aimed to assess the effect of a single, low dose of $\mathrm{CPH}$ before a breakfast meal on postprandial acylated ghrelin concentration and sensations associated with appetite in healthy, middle-aged to elderly subjects.

\section{Material and methods}

Data on subjects and methods have been described in detail in a previous publication (14).

\section{Trial design}

The study was a double-blind crossover trial, which included two study visits for each subject, with 4-7 days of washout in between. The intervention included serving of a test drink containing $20 \mathrm{mg}$ of $\mathrm{CPH}$ per $\mathrm{kg}$ body weight (test material) or control (casein) in randomized order, immediately before a standardized breakfast meal was served. The $\mathrm{CPH}$ and casein powder were mixed with cold water and served as a drink. The primary outcome of the intervention (postprandial response in glucose metabolism) is reported in a previous publication (14). Here, we report the secondary outcome: acylated ghrelin concentrations measured for 180 min postprandially and subjective sensations associated with appetite.

This study was conducted according to the guidelines laid down in the Declaration of Helsinki, and all procedures were approved by the Regional Committees for Medical and Health Research Ethics of Central Norway (2017/1794). Written informed consent was obtained from all subjects. The trial was registered at clinicaltrials.gov as NCT03669796.

\section{Participants}

Subjects were recruited at Haukeland University Hospital and Ålesund Hospital between October 2017 and February 2018. Potential subjects were interviewed for general eligibility and compliance with inclusion and exclusion criteria by telephone. Candidates were invited for a further screening visit.

Inclusion criteria were as follows: age 40-65 years and body mass index (BMI) $20-30 \mathrm{~kg} / \mathrm{m}^{2}$. Exclusion criteria were fish allergy, pharmacologically treated diabetes mellitus, elevated blood pressure, chronic diseases that might affect the evaluation of the study endpoints, and acute infections. 


\section{Study protocol}

The screening visit included a clinical examination by a physician, biochemistry tests for safety purposes (leukocyter, trombocytes, hemoglobin, fasting glucose, long-term blood glucose, C-reactive protein, creatinine, sodium, potassium, kidney function estimate, liver enzymes and muscle enzymes) and compliance with inclusion criteria, measuring of height, weight, and blood pressure, as well as assessment of the level of physical activity. The level of physical activity was assessed by asking the participants two questions regarding moderate physical activity and vigorous activity (self-reported). The participants were instructed not to change the diet composition or the level of physical activity during the study period. On the day preceding each study day, the participants received a standardized porridge evening meal to be eaten before 8:30 pm. After this, the subjects were instructed to fast until the next morning and were only allowed to drink water. On study days, the participants came to the research units in a fasting state between 08:00 am and 09:00 am. After the first blood sample, the subjects were served the test drink, before the breakfast meal was provided. Fifteen minutes after the breakfast was served, the first post-meal sample ( 0 min sample) was taken.

The standardized breakfast meal consisted of two slices of bread (50\% whole wheat, $80 \mathrm{~g}$ bread), $10 \mathrm{~g}$ margarine, $20 \mathrm{~g}$ strawberry jam, and $20 \mathrm{~g}$ white cheese. This provided a total of $355 \mathrm{kcal}(1,485 \mathrm{~kJ}, 41 \mathrm{~g}$ carbohydrate, $12.5 \mathrm{~g}$ protein, $15 \mathrm{~g}$ fat). The drink contained on average $35.9 \mathrm{~g}$ carbohydrate and $145 \mathrm{kcal}(607 \mathrm{~kJ})$. Thus, including the drink, the breakfast provided in total $500 \mathrm{kcal}(2,092 \mathrm{~kJ})$ and $77 \mathrm{~g}$ carbohydrate, equal at both study days. Water was given ad libitum, but no coffee or tea was allowed. The subjects spent $4 \mathrm{~h}$ in the research units, and repeated sampling of blood was conducted before serving of the test drink and breakfast, and at time $0,20,40,80$, and 180 min postprandially.

\section{Assessments}

Assessment of medical history, measurement of biochemical variables and safety parameters were conducted before randomization. During the two study visits, acylated ghrelin was measured in plasma samples taken before serving of the test drink and breakfast (baseline), at time $0,20,40,80$, and 180 min postprandially. The subjects had 15 min to finish the breakfast before the 0 min sample was taken. Blood pressure was measured before intervention, after 40 and $180 \mathrm{~min}$ after the intervention, as a safety parameter.

Appetite sensation was assessed on a Visual Analog Scale (VAS) of $100 \mathrm{~mm}$ in length, addressing the feeling of fullness and satiety. The VAS questionnaire also included three questions regarding adverse gastrointestinal symptoms (pain, discomfort, and nausea). The VAS was filled out five times during the study visit, at baseline, time 0 and 20, 40, and $180 \mathrm{~min}$ after the breakfast meal. Additionally, a questionnaire validated for the evaluation of different gastrointestinal symptoms was filled out before the breakfast meal and at the end of each study day (21). The questionnaire assessed nausea, bloating, stomach pain, constipation, and diarrhea, as well as hunger/satiety with a score from 0 to 10 , of which the score 10 indicated severe symptoms and being fully satiated.

\section{Test materials}

The test material was a lemon-flavored powder provided from the manufacturer (Firmenich Bjørge Biomarin AS, Allesund, Norway) in standardized bottles to be added $150 \mathrm{~mL}$ cold water. The powder contained $4 \%$ protein (CPH raw material or whole casein) and 96\% carbohydrate (maltodextrin). Thorough laboratory tests assured that it was not possible to identify the active ingredient from the control, according to flavor or appearance. Each subject was given individually adjusted doses of $20 \mathrm{mg} /$ $\mathrm{kg}$ body weight of $\mathrm{CPH}$ or casein. The drinks were made isonitrogenous to avoid bias due to difference in nitrogen content, and equal amounts of nitrogen in the form of casein were added to the control drink. Both drinks contained on average $1.6 \mathrm{~g}$ protein; thus it constituted only a small fraction of the total protein content of the standardized breakfast meal. Casein was chosen as the control as it has previously shown to not affect blood glucose or insulin sensitivity when compared with proteins from cod and soya (22). The casein used as control was present as whole protein and did not contain free amino acids or peptides. The production and composition of the test materials has been described in detail in previous publication (14).

\section{Analysis of blood samples}

Samples of venous blood were repeatedly collected using an intravenous catheter from the antecubital vein. Samples were analyzed according to standard accredited methods at the Laboratory for Clinical Biochemistry, Haukeland University Hospital (Bergen, Norway) and the Department of Medical Biochemistry, Ålesund Hospital (Ålesund, Norway).

Plasma ghrelin was obtained by centrifugation of full blood using $4 \mathrm{~mL}$ anticoagulant (EDTA-K3)/Aprotinin blood collecting tubes (VACUETTE®, Greiner Bio One International $\mathrm{GmbH}$, cat \# 454261, Kremsmünster, Austria) at $1800 \times g$ at $4^{\circ} \mathrm{C}$ for 10 min within 20 min after blood sampling. Plasma was stored frozen at $-80^{\circ} \mathrm{C}$ prior to analysis. The ghrelin analyses were performed using Acylated Ghrelin-Easy Sampling Enzyme Immunoassay kit (Bertin Pharma, Montigny-le-Bretonneux, France, ref: \#A11306). 


\section{Statistical analysis}

SPSS data package (SPSS Statistics 24.0, IBM Company, Armonk, NY, USA) and GraphPad Prism version 7.0 (GraphPad Software, Inc., San Diego, CA, USA) were used for statistical analysis. Shapiro-Wilk's test was conducted to assess normal distribution of data. A multivariable, repeated-measures linear mixed-effects regression analysis (adjusted for BMI and gender) was conducted in SPSS in order to evaluate the difference between the concentrations of acylated ghrelin after $\mathrm{CPH}$ and control. The data for acylated ghrelin were non-normally distributed; thus, it was log-transformed before analysis and presented as log mean and back-transformed values (geometric means). Graphical work and total area under the curve (tAUC) analysis for acylated ghrelin concentrations and symptom VAS-scores were conducted in GraphPad. The difference in baseline and end-point scores for the additional questionnaire was evaluated by a paired $t$-test. Assessment of correlations was done with Pearson's correlation coefficient. $P$-values $<0.05$ were considered statistically significant.

The number of participants was not calculated according to a power analysis, due to lack of similar studies. Previous research reporting on effect of cod proteins in humans is based on whole fish (23) or long-term use of fish protein supplement $(12,13)$; thus, we did not find any data suitable as basis for power analysis for our design.

\section{Results}

\section{Subjects}

Seventy-eight subjects were screened for inclusion and exclusion criteria over telephone, of which 47 were enrolled to a screening visit. Six participants withdrew before the first study visit, and 41 participants completed the trial, of which 15 males and 26 females. The inclusion process has previously been described and illustrated (14). The mean age of the participants was $51 \pm 6$ years (range 40-64 years). The mean body weight of the participants was $77.3 \pm 13.5 \mathrm{~kg}$. Dependent on body weight, the subjects consumed $\mathrm{CPH}$ in a dose ranging from 1.2 to $2.3 \mathrm{~g}$ (mean
$1.5 \mathrm{~g})$. Mean BMI was $25.2 \pm 3 \mathrm{~kg} / \mathrm{m}^{2}$. Twenty-three participants had BMI $\leq 25 \mathrm{~kg} / \mathrm{m}^{2}$, whereas 18 participants had $\mathrm{BMI}>25 \mathrm{~kg} / \mathrm{m}^{2}$. Baseline characteristics and comparison of gender distribution are presented in Table 1.

\section{Acylated ghrelin concentrations}

Mean fasting acylated ghrelin levels were higher before the $\mathrm{CPH}$ intervention than before the control intervention $(97.4 \pm 196.3 \mathrm{pg} / \mathrm{mL}$ vs. $90.0 \pm 194.0 \mathrm{pg} / \mathrm{mL}$, respectively), but the difference was not significant $(P>0.999)$. Suppression of acylated ghrelin $\left(\mathrm{C}_{\min }\right)$ was greatest: 80 min postprandially after $\mathrm{CPH}$ and 20 min postprandially after control, with a $\mathrm{C}_{\text {min }}$ mean difference from baseline of $-14.0 \pm 21.4$ after $\mathrm{CPH}$ and $-5.3 \pm 22.8$ after control, at these times, respectively $(P=0.681)$.

Statistically, no differences were observed between $\mathrm{CPH}$ and control for postprandial acylated ghrelin concentration in a mixed-effects regression analysis (mean difference of the geometric mean: $1.05 \mathrm{pg} / \mathrm{mL}, 95 \%$ confidence interval $[\mathrm{CI}]$ : $0.97-1.13, P=0.266$ ) (Fig. 1). Additionally,

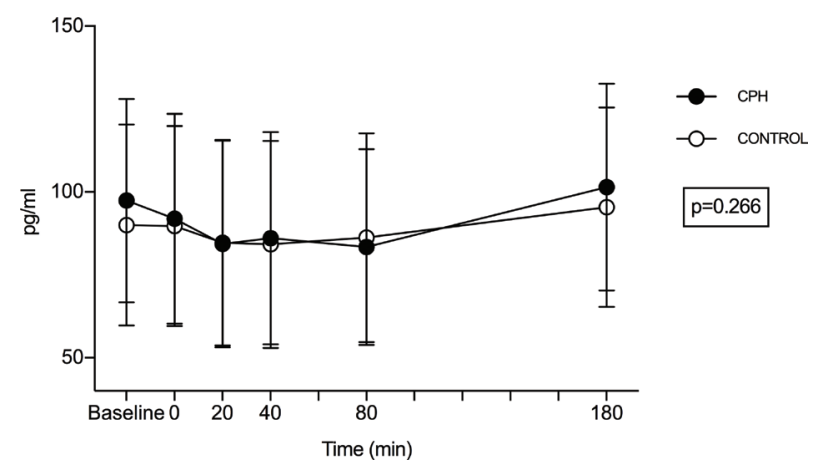

Fig. 1. Metabolic response in acylated ghrelin concentration after intake of a standardized breakfast meal supplemented with a drink containing a cod protein hydrolysate $(\mathrm{CPH})$ or control (casein). Results are presented for 41 healthy subjects. Time point 0 min shows values measured right after the intake of breakfast and test drink. Values are presented as mean + SD. Statistically, no differences were observed between $\mathrm{CPH}$ and control for acylated ghrelin concentration in a mixed-model regression analysis $(P=0.266)$.

Table 1. Baseline characteristics of the 41 participants (26 females and 15 males) included in the study at the Haukeland University Hospital and Ålesund Hospital

\begin{tabular}{|c|c|c|c|c|c|c|c|}
\hline \multirow[t]{2}{*}{ Characteristics } & \multicolumn{2}{|c|}{ Total subjects $(n=4 I)$} & \multicolumn{2}{|c|}{ Female $(n=26)$} & \multicolumn{2}{|c|}{ Male $(n=15)$} & \multirow[t]{2}{*}{$P$} \\
\hline & Mean & Standard deviation & Mean & Standard deviation & Mean & Standard deviation & \\
\hline Age, years & 51.0 & 6.0 & 52.1 & 6.2 & 49.0 & 5.0 & 0.104 \\
\hline Body weight & 77.3 & 13.5 & 71.6 & 10.8 & 87.2 & 12.3 & 0.001 \\
\hline Body mass index, $\mathrm{kg} / \mathrm{m}^{2}$ & 25.2 & 3.0 & 24.7 & 3.0 & 26.0 & 2.9 & 0.183 \\
\hline Acylated ghrelin, pg/mL & 93.7 & 194.9 & 81.4 & 184.7 & 115.0 & 210.6 & 0.453 \\
\hline
\end{tabular}

Baseline acylated ghrelin concentrations are merged values for the baseline value at both study visits. 
a)

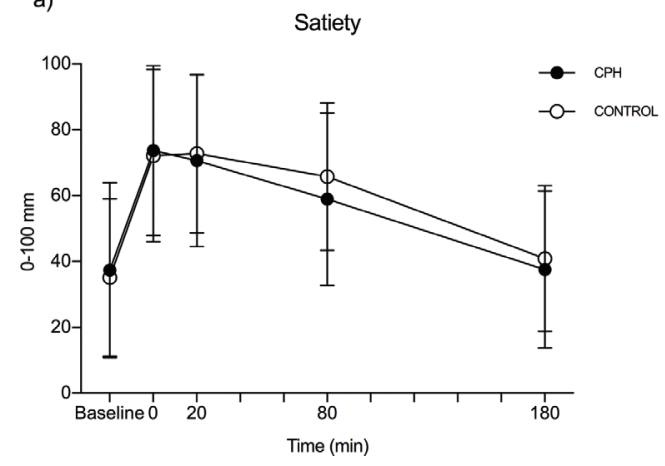

b)

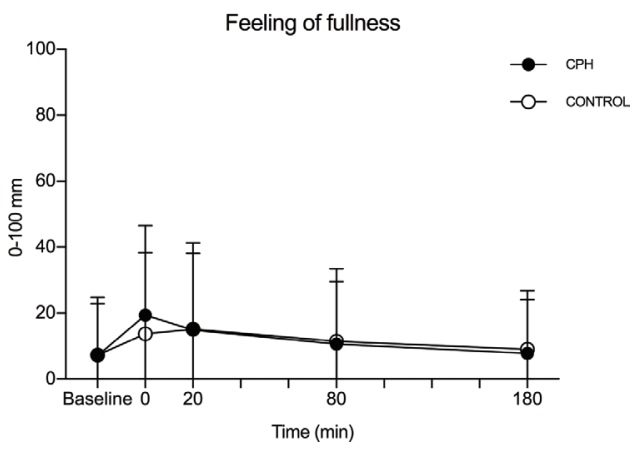

Fig. 2. Symptom scores from a VAS-questionnaire addressing satiety (a) and the feeling of fullness (b) after intake of a standardized breakfast meal supplemented with a drink containing either a cod protein hydrolysate (CPH) or control (casein). Results are presented for 41 healthy subjects. Time point 0 min shows values measured right after the intake of breakfast and test material. Values are presented as mean + SD. Statistically, no differences were found between CPH and control for sensation of appetite, according to the tAUC of postprandial scores for satiety $(P=0.794)$ and the feeling of fullness $(P=0.966)$.

no difference was observed between the tAUC for acylated ghrelin concentrations after $\mathrm{CPH}(\mathrm{tAUC}=17518 \mathrm{pg} /$ $\mathrm{mL} \times \min , 95 \%$ CI: $0-47941)$ and control (tAUC $=$ $17272 \mathrm{pg} / \mathrm{mL} \times \min , 95 \%$ CI: $0-48048, P=0.991)$.

No correlation was observed between body weight $(\mathrm{kg})$ and baseline concentration of acylated ghrelin (mean baseline value before $\mathrm{CPH}$ and control) $(r=0.118$, $P=0.463)$. When adjusting for BMI and gender in the mixed-effects regression analysis, no differences were observed between subjects with BMI $\leq 25 \mathrm{~kg} / \mathrm{m}^{2}$ compared to those with BMI $>25 \mathrm{~kg} / \mathrm{m}^{2}(P=0.681)$, or between genders $(P=0.627)$.

\section{Sensation of appetite}

Baseline scores for satiety were numerically the same before each intervention (CPH: $37.4 \pm 26.6$, control: $35.1 \pm 23.9, P=0.997)$. No difference was observed between the tAUC for the postprandial satiety scores after CPH (tAUC $=10989 \mathrm{~mm} \times \min , 95 \%$ CI: 6794$15185)$ and control (tAUC $=11742 \mathrm{~mm} \times \min , 95 \% \mathrm{CI}$ : 8001-15483, $P=0.794)$. Data are presented in Fig. 2a.

Baseline scores for the feeling of fullness were numerically the same before each intervention $(\mathrm{CPH}$ : $7.1 \pm 15.7$, control: $7.3 \pm 17.5, P>0.999)$. No difference was observed between the tAUC for the postprandial feeling of fullness scores after $\mathrm{CPH}(\mathrm{tAUC}=$ $1306 \mathrm{~mm} \times \min , 95 \%$ CI: 0-3257) and control (tAUC $=$ $1243 \mathrm{~mm} \times \min , 95 \% \mathrm{CI}: 0-3418, P=0.966)$. Data are presented in Fig. 2 b.

The questionnaire addressing hunger did not reveal any differences in the feeling of satiety and hunger between CPH (3.4 \pm 1.8$)$ and control (3.4 \pm 2.3$) 180$ min after the breakfast $(P=0.822)$. Baseline scores did not differ before each intervention (CPH: $3.7 \pm 2.7$ and control: $3.0 \pm 2.5$, $P=0.165)$.

\section{Gastrointestinal symptoms}

There were no reports of adverse gastrointestinal symptoms (e.g. nausea, bloating, stomach pain, constipation, or diarrhea) during the exposure for either $\mathrm{CPH}$ or control.

\section{Discussion}

This study revealed no differences in postprandial concentrations of acylated ghrelin after a meal supplemented with $\mathrm{CPH}$ compared to control. Thus, we were unable to confirm our hypothesis that a single dose of $\mathrm{CPH}$ supplementation before a meal would suppress ghrelin concentrations postprandially, and thereby cause reduced feeling of hunger. Moreover, we found no differences between control and $\mathrm{CPH}$ drink in the feeling of satiety or feeling of fullness, as measured by the implemented questionnaires.

In a previous publication, we reported that supplementation with $20 \mathrm{mg} \mathrm{CPH}$ per $\mathrm{kg}$ body weight before a breakfast meal reduced the postprandial concentrations of insulin compared to control in healthy individuals (14). Although not affecting glucose levels or concentrations of GLP-1, we found that pre-prandial supplementation with one low dose of CPH may beneficially alter the glucose metabolism. An inverse correlation between postprandial insulin concentrations and plasma ghrelin has previously been reported (24), and changes in ghrelin concentration after $\mathrm{CPH}$ might affect postprandial insulin secretion. The major effects of ghrelin are linked to mechanisms involved in avoiding starvation and promoting food intake and include stimulation of GH secretion to restrict peripheral glucose uptake, promote lipolysis, and suppress insulin secretion to prevent hypoglycemia (25). Due to this close link between glucose metabolism and appetite control, it can be hypothesized that supplementation with $\mathrm{CPH}$ might influence 
postprandial ghrelin concentrations and the feeling of hunger and satiety.

Our results are partly in line with previous similar single-dose studies; however, few studies are comparable in test material. Most studies investigating the relationship between ghrelin levels after meals with different macronutrient composition have found that a high-protein meal causes the ghrelin levels to be suppressed for a longer time than after the intake of a meal high in carbohydrates (26-31). Furthermore, it causes higher satiety scores postprandially than a meal containing regular or low amount of protein $(28,32)$. The mechanisms suggested to facilitate these findings include slowing of gastric emptying, increase of plasma insulin, glucagon, ghrelin, CCK, gastric inhibitory polypeptide (GIP), and GLP-1 after a high-protein meal (33).

Only a few studies have reported on the specific acute postprandial effect of a meal with proteins from fish, compared to other protein sources (34-36). A comparison of the effects of isocaloric meals with proteins from beef, chicken, or fish revealed a significantly higher satiety score after the fish meal compared to the other protein sources (34). A study evaluating the effect on satiety when comparing a fish protein meal with a beef protein meal revealed that subjects receiving the fish-meal had lower hunger scores and consumed less energy in the subsequent evening meal (36). In contrast, a study investigating the acute effect of meals based on proteins from cod or veal in combination with carbohydrates high- or low-glycemic index did not find any differences in appetite sensation, energy intake, or postprandial response in glucose, insulin, or ghrelin levels when comparing the two different protein sources (35). Although some previous studies have reported fish proteins to suppress appetite, no effect has this far been reported for the levels of ghrelin. One previous study has reported on the specific hunger-regulating effect of a fish protein hydrolysate from blue whiting (2 g/day) (17). The fish protein hydrolysate was reported to suppress appetite when compared to placebo in a 2-week crossover trial in overweight women. According to postprandial measures after a standardized breakfast meal, it was observed that the fish protein hydrolysate significantly reduced sweet-cravings, as well as plasma glucose levels compared to placebo. This study was based on observations made in both in vitro and in vivo models, showing that the fish protein hydrolysate was capable of enhancing the secretion of CCK and GLP-1, both hormones contributing to the regulation of energy intake (37).

In the present study, we hypothesized that a potential suppressing effect on appetite and postprandial ghrelin levels would occur due to the $\mathrm{CPH}$ containing a high fraction of di- and tripeptides with the branched-chain amino acids leucine and isoleucine. We hypothesize that these peptides work as biologically active substances, which are rapidly absorbed from the gastrointestinal tract and possibly capable of influencing pathways involved in the regulation of appetite. Thus, a single low dose of peptides was administered to the participants. The amount of protein provided was so low that it can be regarded negligible per se, compared to the amount of protein provided in the breakfast meal. Several factors could explain the lack of observed effect. First, it is possible that one acute exposure of the low concentration is not enough to induce the wanted effect. A different effect could might have been observed if the participants had taken the CPH supplement daily for a period of time, for instance over a period of $6-8$ weeks.

A similar dose of $\mathrm{CPH}$ as the one administered in our trial, has previously been reported to increase concentrations of CCK and GLP-1 compared to placebo in a study including 120 overweight individuals given either 1.4 or $2.8 \mathrm{~g}$ protein hydrolysate from blue whiting or placebo, for 90 days (18). The fish protein hydrolysate was found to be effective compared to placebo, but no difference in effect was observed between the two doses. This demonstrates a potential effect when $\mathrm{CPH}$ is administered orally in doses of approximately $15-20 \mathrm{mg}$ per $\mathrm{kg}$ body weight. In our study, the subjects consumed $\mathrm{CPH}$ in a dose range from 1.2 to $2.3 \mathrm{~g}$ (mean $1.5 \mathrm{~g}$ ), dependent on body weight. Thus, if an effect was to be observed, this could possibly have been attributed to the presence of bioactive peptides.

The results have to be interpreted taking certain strengths and limitations into account. First, the randomized, crossover design as well as the successful blinding with similar test drink and control is a strength of this study. Furthermore, the adjustment of peptide dose according to the body weight of each participant can be regarded as an improvement in accuracy compared to previous investigations of protein meals and the few studies investigating a marine protein hydrolysate, as this may reduce the effect of variation in body weight. It can be regarded a weakness of the design that the control drink contained casein in equal amounts as $\mathrm{CPH}$, and that we did not include a true placebo without protein. However, as discussed above, the hypothesized effect is attributed to the presence of bioactive peptides and not protein per se. Whole casein was chosen as control, so the observed effect should not be simply due to differences in energy and nitrogen content. Casein has previously been shown to not affect glucose metabolism when given in low concentrations (38). We could arguably have investigated the effect of $\mathrm{CPH}$ on several different hunger-regulating hormones, for instance, CCK, which has been measured in few other studies investigating the effect of a fish protein hydrolysate on appetite $(17,18)$. The assessment of appetite could have been improved by using a more comprehensive instrument at all timepoints (39). However, 
the use of VAS ratings in the evaluation of appetite in healthy subjects is a previously validated method (40). An ad libitum lunch meal with subsequent calculations of actual energy intake after $\mathrm{CPH}$ and control could have been included for a better and more detailed investigation of appetite. Furthermore, it is possible that the lack of sufficient previous data to perform a power analysis could result in too few included participants to be able to observe an effect. We decided to include 40 participants, a number greater than or equal to previously reported studies on cod protein $(12,13,23)$.

Further studies should aim to evaluate the impact of fish protein hydrolysates on different metabolic pathways involved in glucose metabolism and appetite control, such as regulation of different hunger-regulating hormones. In addition to ghrelin, insulin-like peptide 5 (INSL5) is quite recently suggested to be an orexigenic hormone influencing appetite and regulation of food intake (41). Thus, future studies should aim to evaluate the appetite-regulating effect of CPH on several hormones, including INSL5. Assessments of such response can arguably contribute to the expansion of knowledge on the effects of $\mathrm{CPH}$, as well as possibly reveal new preventive and treatment options for overweight and obesity. Based on the current literature, the effect could be more apparent if the fish protein hydrolysate had been given daily over a period of time, and if it had been investigated in a target group of overweight and obese individuals. Thus, the design of future studies should take this into account.

In conclusion, we did not find any effect of a single dose of $\mathrm{CPH}$ on postprandial concentrations of acylated ghrelin, or sensations-related appetite in healthy individuals, when compared to control after a standardized breakfast meal.

\section{Acknowledgments}

Stine Rødal Martiniussen, Per Førde Refsnes and Linda Norunn Bratli helped with sampling of blood and practical implementation in Bergen. The Clinical Research unit at Ålesund Hospital, Møre \& Romsdal Hospital trust, helped with blood sampling and practical implementations in Ålesund.

\section{Founding}

This work was funded by the Norwegian Council of Research (grant number 256684), Haukeland University Hospital, the University of Bergen, Ålesund Hospital and Firmenich Bjørge Biomarin AS.

\section{Authors}

HFD, CJ, TH, IB, JGH, DALH and GAL designed the present study. HFD and CJ conducted the research. IB analysed the ghrelin samples. HFD wrote the manuscript.
EL obtained funding and provided administrative, technical and material support. All authors reviewed and approved the manuscript.

\section{Disclosure}

Einar Lied is professor emeritus at the University of Bergen, Bergen, Norway, and former Scientific Advisor in Firmenich Bjørge Biomarin AS (Ellingsøy, Ålesund, Norway), where he holds a royalty agreement. The other authors declare no conflict of interest.

\section{References}

1. Cummings DE. Ghrelin and the short- and long-term regulation of appetite and body weight. Physiol Behav 2006; 89(1): 71-84. doi: 10.1016/j.physbeh.2006.05.022

2. Kojima M, Hosoda H, Date $Y$, Nakazato M, Matsuo H, Kangawa K. Ghrelin is a growth-hormone-releasing acylated peptide from stomach. Nature 1999; 402(6762): 656-60. doi: $10.1038 / 45230$

3. Cummings DE, Purnell JQ, Frayo RS, Schmidova K, Wisse BE, Weigle DS. A preprandial rise in plasma ghrelin levels suggests a role in meal initiation in humans. Diabetes 2001; 50(8): 1714-9. doi: 10.2337/diabetes.50.8.1714

4. Nakazato M, Murakami N, Date Y, Kojima M, Matsuo H, Kangawa K, et al. A role for ghrelin in the central regulation of feeding. Nature 2001; 409(6817): 194-8. doi: 10.1038/35051587

5. Broglio F, Arvat E, Benso A, Gottero C, Muccioli G, Papotti M, et al. Ghrelin, a natural GH secretagogue produced by the stomach, induces hyperglycemia and reduces insulin secretion in humans. J Clin Endocrinol Metab 2001; 86(10): 5083-6. doi: 10.1210/jcem.86.10.8098

6. Tong J, Davis HW, Gastaldelli A, D'Alessio D. Ghrelin impairs prandial glucose tolerance and insulin secretion in healthy humans despite increasing GLP-1. J Clin Endocrinol Metab 2016; 101(6): 2405-14. doi: 10.1210/jc.2015-4154

7. Faulconbridge LF, Cummings DE, Kaplan JM, Grill HJ. Hyperphagic effects of brainstem ghrelin administration. Diabetes 2003; 52(9): 2260-5. doi: 10.2337/diabetes.52.9.2260

8. Meyer C. Final answer: ghrelin can suppress insulin secretion in humans, but is it clinically relevant? Diabetes 2010; 59(11): 2726-8. doi: $10.2337 / \mathrm{db} 10-1088$

9. Castaneda TR, Tong J, Datta R, Culler M, Tschop MH. Ghrelin in the regulation of body weight and metabolism. Front Neuroendocrinol 2010; 31(1): 44-60. doi: 10.1016/j.yfrne.2009.10.008

10. Tong J, Prigeon RL, Davis HW, Bidlingmaier M, Kahn SE, Cummings DE, et al. Ghrelin suppresses glucose-stimulated insulin secretion and deteriorates glucose tolerance in healthy humans. Diabetes 2010; 59(9): 2145-51. doi: 10.2337/db10-0504

11. Tremblay F, Lavigne C, Jacques H, Marette A. Role of dietary proteins and amino acids in the pathogenesis of insulin resistance. Annu Rev Nutr 2007; 27: 293-310. doi: 10.1146/annurev. nutr.25.050304.092545

12. Vikoren LA, Nygard OK, Lied E, Rostrup E, Gudbrandsen OA. A randomised study on the effects of fish protein supplement on glucose tolerance, lipids and body composition in overweight adults. Br J Nutr 2013; 109(4): 648-57. doi: 10.1017/ S0007114512001717

13. Vildmyren I, Cao HJV, Haug LB, Valand IU, Eng O, Oterhals A, et al. Daily intake of protein from cod residual material 
lowers serum concentrations of nonesterified fatty acids in overweight healthy adults: a randomized double-blind pilot study. Mar Drugs 2018; 16(6): E197. doi: 10.3390/md16060197

14. Dale HF, Jensen C, Hausken T, Lied E, Hatlebakk JG, Brønstad I, et al. Effect of a cod protein hydrolysate on postprandial glucose metabolism in healthy subjects: a double-blind cross-over trial. J Nutr Sci 2018; 7: e33. doi: 10.1017/jns.2018.23

15. Drotningsvik A, Mjos SA, Pampanin DM, Slizyte R, Carvajal A, Remman T, et al. Dietary fish protein hydrolysates containing bioactive motifs affect serum and adipose tissue fatty acid compositions, serum lipids, postprandial glucose regulation and growth in obese Zucker fa/fa rats. Br J Nutr 2016; 116(8): 1336-45. doi: 10.1017/S0007114516003548

16. Liaset B, Madsen L, Hao Q, Criales G, Mellgren G, Marschall HU, et al. Fish protein hydrolysate elevates plasma bile acids and reduces visceral adipose tissue mass in rats. Biochim Biophys Acta 2009; 1791(4): 254-62. doi: 10.1016/j. bbalip.2009.01.016

17. Zaïr Y, Duclos E, Housez B, Vergara C, Cazaubiel M, Soisson F. Evaluation of the satiating properties of a fish protein hydrolysate among overweight women: a pilot study. Nutr Food Sci 2014; 44(5): 389-99. doi:10.1108/NFS-06-2013-0075

18. Nobile V, Duclos E, Michelotti A, Bizzaro G, Negro M, Soisson F. Supplementation with a fish protein hydrolysate (Micromesistius poutassou): effects on body weight, body composition, and CCK/GLP-1 secretion. Food Nutr Res 2016; 60: 29857. doi: 10.3402/fnr.v60.29857

19. Ministers NCo. Nordic Nutrition Recommendations 2012: integrating nutrition and physical activity. Copenhagen: Nordic Council of Ministers; 2014; 1-627. doi: 10.6027/ Nord2014-002

20. Le Gouic AV, Harnedy PA, FitzGerald RJ. Bioactive peptides from fish protein by-products. In: Mérillon J-M, Ramawat KG, eds. Bioactive molecules in food. Cham: Springer International Publishing; 2018, pp. 1-35. doi: 10.1007/978-3-319-54528-8_29-1

21. Kane SV, Sandborn WJ, Rufo PA, Zholudev A, Boone J, Lyerly $\mathrm{D}$, et al. Fecal lactoferrin is a sensitive and specific marker in identifying intestinal inflammation. Am J Gastroenterol 2003; 98(6): 1309-14. doi: 10.1111/j.1572-0241.2003.07458.x

22. Lavigne C, Tremblay F, Asselin G, Jacques H, Marette A. Prevention of skeletal muscle insulin resistance by dietary cod protein in high fat-fed rats. Am J Physiol Endocrinol Metab 2001; 281(1): E62-71. doi: 10.1152/ajpendo.2001.281.1.E62

23. Ouellet V, Marois J, Weisnagel SJ, Jacques H. Dietary cod protein improves insulin sensitivity in insulin-resistant men and women: a randomized controlled trial. Diabetes Care 2007; 30(11): 2816-21. doi: 10.2337/dc07-0273

24. Erdmann J, Topsch R, Lippl F, Gussmann P, Schusdziarra V. Postprandial response of plasma ghrelin levels to various test meals in relation to food intake, plasma insulin, and glucose. J Clin Endocrinol Metab 2004; 89(6): 3048-54. doi: 10.1210/ jc. 2003-031610

25. Heppner KM, Tong J. Mechanisms in endocrinology: regulation of glucose metabolism by the ghrelin system: multiple players and multiple actions. Eur J Endocrinol 2014; 171(1): R21-32. doi: 10.1530/EJE-14-0183

26. Blom WA, Lluch A, Stafleu A, Vinoy S, Holst JJ, Schaafsma $\mathrm{G}$, et al. Effect of a high-protein breakfast on the postprandial ghrelin response. Am J Clin Nutr 2006; 83(2): 211-20. doi: 10.1093/ajcn/83.2.211

27. Foster-Schubert KE, Overduin J, Prudom CE, Liu J, Callahan HS, Gaylinn BD, et al. Acyl and total ghrelin are suppressed strongly by ingested proteins, weakly by lipids, and biphasically by carbohydrates. J Clin Endocrinol Metab 2008; 93(5): 1971-9. doi: $10.1210 /$ jc. $2007-2289$

28. Leidy HJ, Mattes RD, Campbell WW. Effects of acute and chronic protein intake on metabolism, appetite, and ghrelin during weight loss. Obesity (Silver Spring, Md) 2007; 15(5): 1215-25. doi: 10.1038/oby.2007.143

29. Tannous dit El Khoury D, Obeid O, Azar ST, Hwalla N. Variations in postprandial ghrelin status following ingestion of high-carbohydrate, high-fat, and high-protein meals in males. Ann Nutr Metab 2006; 50(3): 260-9. doi: 10.1159/ 000091684

30. Giezenaar C, Lange K, Hausken T, Jones KL, Horowitz M, Chapman I, et al. Acute effects of substitution, and addition, of carbohydrates and fat to protein on gastric emptying, blood glucose, gut hormones, appetite, and energy intake. Nutrients 2018; 10(10): E1451. doi: 10.3390/nu10101451

31. Giezenaar C, Luscombe-Marsh ND, Hutchison AT, Lange K, Hausken T, Jones KL, et al. Effect of gender on the acute effects of whey protein ingestion on energy intake, appetite, gastric emptying and gut hormone responses in healthy young adults. Nutr Diabetes 2018; 8(1): 40. doi: 10.1038/ s41387-018-0048-7

32. Smeets AJ, Soenen S, Luscombe-Marsh ND, Ueland O, Westerterp-Plantenga MS. Energy expenditure, satiety, and plasma ghrelin, glucagon-like peptide 1, and peptide tyrosine-tyrosine concentrations following a single highprotein lunch. J Nutr 2008; 138(4): 698-702. doi: 10.1093/ jn/138.4.698

33. Hutchison AT, Piscitelli D, Horowitz M, Jones KL, Clifton PM, Standfield S, et al. Acute load-dependent effects of oral whey protein on gastric emptying, gut hormone release, glycemia, appetite, and energy intake in healthy men. Am J Clin Nutr 2015; 102(6): 1574-84. doi: 10.3945/ajen.115.117556

34. Uhe AM, Collier GR, O'Dea K. A comparison of the effects of beef, chicken and fish protein on satiety and amino acid profiles in lean male subjects. J Nutr 1992; 122(3): 467-72. doi: 10.1093/ $\mathrm{jn} / 122.3 .467$

35. Nielsen LV, Nyby S, Klingenberg L, Juul-Hindsgaul N, Rudnicki $\mathrm{J}$, Ritz C, et al. Meals based on cod or veal in combination with high or low glycemic index carbohydrates did not affect diet-induced thermogenesis, appetite sensations, or subsequent energy intake differently. Appetite 2018; 130: 199-208. doi: 10.1016/j. appet.2018.08.006

36. Borzoei S, Neovius M, Barkeling B, Teixeira-Pinto A, Rossner $\mathrm{S}$. A comparison of effects of fish and beef protein on satiety in normal weight men. Eur J Clin Nutr 2006; 60(7): 897-902. doi: 10.1038/sj.ejcn.1602397

37. Cudennec B, Fouchereau-Peron M, Ferry F, Duclos E, Ravallec R. In vitro and in vivo evidence for a satiating effect of fish protein hydrolysate obtained from blue whiting (Micromesistius poutassou) muscle. J Funct Foods 2012; 4(1): 271-7. doi: 10.1016/j.jff.2011.12.003

38. Schmedes M, Bendtsen LQ, Gomes S, Liaset B, Holst JJ, Ritz C, et al. The effect of casein, hydrolyzed casein and whey proteins on urinary and postprandial plasma metabolites in overweight and moderately obese human subjects. J Sci Food Agric 2018; 98(15): 5598-5605. doi: 10.1002/jsfa.9103

39. Blundell J, de Graaf C, Hulshof $T$, Jebb S, Livingstone B, Lluch A, et al. Appetite control: methodological aspects of the evaluation of foods. Obes Rev 2010; 11(3): 251-70. doi: 10.1111/j.1467-789X.2010.00714.x 
40. Parker BA, Sturm K, MacIntosh CG, Feinle C, Horowitz M, Chapman IM. Relation between food intake and visual analogue scale ratings of appetite and other sensations in healthy older and young subjects. Eur J Clin Nutr 2004; 58(2): 212-8. doi: 10.1038/sj.ejcn.1601768

41. Grosse J, Heffron H, Burling K, Akhter Hossain M, Habib AM, Rogers GJ, et al. Insulin-like peptide 5 is an orexigenic gastrointestinal hormone. Proc Natl Acad Sci USA 2014; 111(30): 11133-8. doi: 10.1073/pnas.1411413111

\section{*Hanna Fjeldheim Dale}

Centre for Nutrition

Department of Clinical Medicine

University of Bergen

Haukelandsbakken I5

5009 Bergen

Norway

Email:hanna.dale@outlook.comv 